\title{
An exploration study to find important factors influencing on decision support systems
}

\author{
Naser Azad*, Mohammad Sadeghi, Seyed Foad Zarifi and Mohammad Reza Farkian
}

Department of Management, Islamic Azad University, South Tehran Branch, Tehran, Iran

\begin{tabular}{|c|c|}
\hline CHRON I C LE & ABSTRACT \\
\hline $\begin{array}{l}\text { Article history: } \\
\text { Received May 12, } 2013 \\
\text { Received in revised format } \\
12 \text { August } 2013 \\
\text { Accepted } 14 \text { August } 2013 \\
\text { Available online } \\
\text { August } 152013 \\
\text { Keywords: } \\
\text { Decision support systems } \\
\text { Factor analysis } \\
\text { Municipality }\end{array}$ & $\begin{array}{l}\text { Decision Support Systems (DSSs) are computer-based information systems for } \\
\text { providing necessary supports for business or organizational decision-making } \\
\text { activities. DSSs often serve the management, operations, and planning levels of all } \\
\text { organizations and help to make decisions, which may be rapidly changing and not } \\
\text { easily achieved in advance. This paper presents an empirical investigation to find } \\
\text { important factors influencing DSSs. The proposed study designs a questionnaire in } \\
\text { Likert scale consists of } 36 \text { questions, distributes it among } 213 \text { employees who work } \\
\text { for different offices in municipality of Tehran, Iran. Cronbach alpha is calculated as } \\
0.872 \text {. In addition, Kaiser-Meyer-Olkin Measure of Sampling Adequacy and Approx. } \\
\text { Chi-Square are } 0.782 \text { and } 1014.521 \text {, respectively. Based on the results of our survey, } \\
\text { we have derived three factors including system, analysis and transaction. }\end{array}$ \\
\hline
\end{tabular}

\section{Introduction}

A Decision Support System (DSS) is considered as a computer-based information system that supports business or organizational decision-making activities (Sanchez et al., 2012). DSSs are responsible to serve the management, operations, and planning levels of organizations and help make decisions, which could be quickly changing and not simply specified in advance and they can be either fully computerized, human or a combination of both. DSSs normally knowledge-based systems where a properly designed DSS is an interactive software-based system applied to help decision makers compile necessary information from a combination of raw data, documents, and personal knowledge, or business models to detect and solve problems and make decisions. There are literally various studies associated with the implementation of DSSs in decision making strategies. 
Siskos et al. (1994) presented an integrated DSS for the analysis and financing of companies by an industrial development bank in Greece. The system evaluated the financial performance of companies in terms of financial ratios of profitability, managerial performance, solvency during a 5-year period and permitted inferences about their development tendencies. In addition, multivariate statistical techniques including discriminant analysis and principal components analysis were used to identify the most significant financial ratios and in the grouping of the firms in coherent categories. The study, a multi-criteria method was implemented, which ranked the firms from the most dynamic to the bankrupt and in this way dynamic to the bank to choose the less risky for financing.

Muhanna (1993) provided an object-oriented framework for model management and DSS development. According to Qian et al. (2012) hesitant fuzzy sets are important to deal with group decision making problems when experts have the access to a hesitation among several possible memberships for an element to a set. Qian et al. (2012) extended hesitant fuzzy sets by intuitionistic fuzzy sets and referred to them as generalized hesitant fuzzy sets. The proposed extension principle appears to enable decision makers to use aggregation operators of intuitionistic fuzzy sets to aggregate a set of generalized hesitant fuzzy sets for decision making.

According to Li et al. (2004), Spatial decision support systems (SDSS) are a branch of data-driven decision support systems that utilize spatial data in the decision-making process. Khademolqorani and Hamadani (2013) presented an adjusted DSS through data mining and multiple criteria decision making. Dong and Srinivasan (2013) presented an agent-enabled service-oriented DSS for managerial decision making. El-Fakdi et al. (2013) presented an in-debt discussion on the implementation of DSS in clinical medications.

\section{The proposed study}

This paper presents an empirical investigation to find important factors influencing DSSs. The proposed study designs a questionnaire in Likert scale consists of 36 questions, distributes it among 213 employees who work for different offices in municipality of Tehran, Iran. Cronbach alpha is calculated as 0.872. In addition, Kaiser-Meyer-Olkin Measure of Sampling Adequacy and Approx. Chi-Square are 0.782 and 1014.521, respectively. Based on the results of our survey, we have derived three factors including system, analysis and transaction. Since we plan to factor analysis and this method is sensitive to skewness of the data we first look at some of the basic statistics including the skewness of the data and decided to remove 25 questions from the survey whose skewness ratios were out of range. Table 1 demonstrates the summary of communalities for the remaining 11 questions.

\section{Table 1}

The summary of communalities extracted by principal component analysis

\begin{tabular}{clcc}
\hline Variable & Description & Initial & Extraction \\
\hline VAR00007 & Service based systems & 1.000 & .589 \\
VAR00009 & Role based systems & 1.000 & .691 \\
VAR00010 & Operational systems & 1.000 & .708 \\
VAR00014 & Data processing & 1.000 & .744 \\
VAR00015 & Data judgment & 1.000 & .602 \\
VAR00017 & Complex systems & 1.000 & .704 \\
VAR00018 & Knowledge based systems & 1.000 & .631 \\
VAR00024 & Detection & 1.000 & .733 \\
VAR00025 & Optimization & 1.000 & .578 \\
VAR00029 & Organizational decision making & 1.000 & .723 \\
VAR00031 & Information system & 1.000 & .643 \\
\hline
\end{tabular}


As we can observe from the results of Table 1 all components maintain well above 50\% communalities with the main factors. Table 2 demonstrates the results of factor analysis on these factors.

Table 2

The summary of principal component analysis after rotation

\begin{tabular}{|c|c|c|c|c|c|c|c|c|c|}
\hline \multirow[b]{2}{*}{ Component } & \multicolumn{3}{|c|}{ Initial Eigenvalues } & \multicolumn{3}{|c|}{ Extraction Sums of Squared Loadings } & \multicolumn{3}{|c|}{ Rotation Sums of Squared Loadings } \\
\hline & Total & $\%$ of Variance & Cumulative \% & Total & $\%$ of Variance & Cumulative \% & Total & $\%$ of Variance & Cumulative \% \\
\hline 1 & 4.763 & 43.296 & 43.296 & 4.763 & 43.296 & 43.296 & 2.793 & 25.394 & 25.394 \\
\hline 2 & 1.412 & 12.833 & 56.129 & 1.412 & 12.833 & 56.129 & 2.314 & 21.038 & 46.432 \\
\hline 3 & 1.172 & 10.655 & 66.784 & 1.172 & 10.655 & 66.784 & 2.239 & 20.352 & 66.784 \\
\hline 4 & .868 & 7.895 & 74.679 & & & & & & \\
\hline 5 & .679 & 6.177 & 80.856 & & & & & & \\
\hline 6 & .625 & 5.681 & 86.537 & & & & & & \\
\hline 7 & .438 & 3.985 & 90.522 & & & & & & \\
\hline 8 & .351 & 3.189 & 93.711 & & & & & & \\
\hline 9 & .250 & 2.276 & 95.987 & & & & & & \\
\hline 10 & .234 & 2.128 & 98.115 & & & & & & \\
\hline 11 & .207 & 1.885 & 100.000 & & & & & & \\
\hline
\end{tabular}

In addition to the results of Table 2, we have looked at Scree plot to determine important factors and the results of figure and Table indicate that there were three factors.

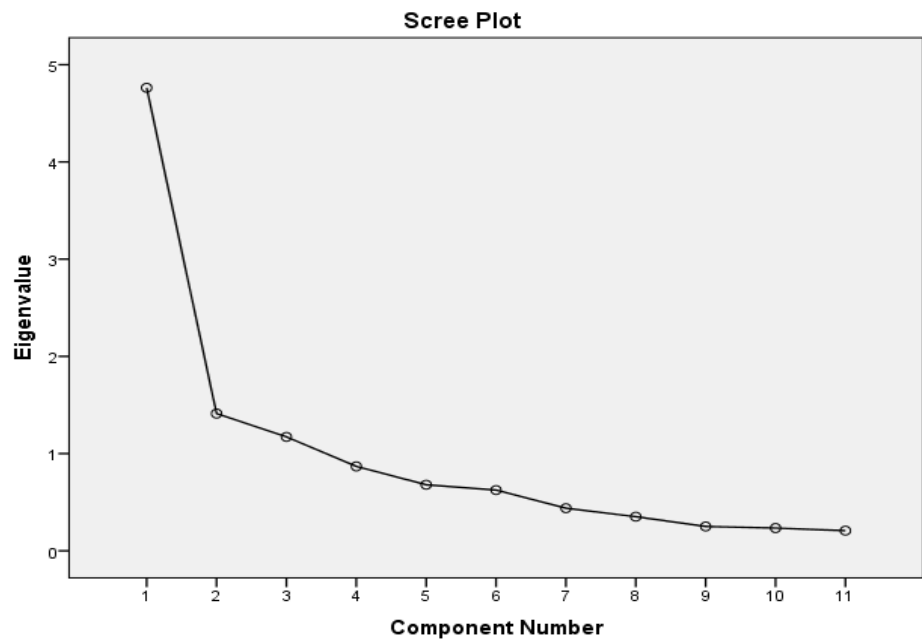

Fig. 1. The results of Scree plot

Based on the results of our survey, we have derived three factors including system, analysis and transaction summarized in Table 3 as follows,

\section{Table 3}

The summary of factor analysis

\begin{tabular}{llcccc}
\hline Factor & Measurable variable & Weight & Eigenvalue & Variance & Accumulated \\
\hline \multirow{5}{*}{ System } & Information system & 0.373 & 1.412 & 56.129 & 56.129 \\
& Organizational decision makers & 0.838 & & & \\
& Service systems & 0.597 & & & \\
& Role based systems & 0.662 & & & \\
& Knowledge based systems & 0.688 & & & \\
\multirow{5}{*}{ Analysis } & Complex systems & 0.559 & 4.763 & & \\
& Optimization & 0.697 & & & \\
& Data judgment & 0.653 & & & \\
\hline \multirow{2}{*}{ Transaction } & Detection & 0.838 & & & \\
\hline
\end{tabular}




\section{Discussion and conclusion}

The results of Table 3 indicate that there were three factors including system, analysis and transaction. In terms of systems, information system is the most important factor followed by organizational decision makers, service systems, role based systems and knowledge based systems. In terms of analysis, complex systems are the most important factor followed by optimization, data judgment and detection. Finally, transaction is the last factor where operational decisions are the most important factor followed by data processing.

\section{Acknowledgment}

The authors would like to thank the anonymous referees for their construction comments on earlier version of this work.

\section{References}

Dong, C. S. J., \& Srinivasan, A. (2013). Agent-enabled service-oriented decision support systems. Decision Support Systems, 55(1), 364-373.

El-Fakdi, A., Gamero, F., Meléndez, J., Auffret, V., \& Haigron, P. (2013). eXiTCDSS: A framework for a workflow-based CBR for interventional Clinical Decision Support Systems and its application to TAVI. Expert Systems with Applications, 32, 438 -452.

Khademolqorani, S., \& Hamadani, A. Z. (2013). An Adjusted Decision Support System through Data Mining and Multiple Criteria Decision Making. Procedia-Social and Behavioral Sciences, 73, 388-395.

Li, Y., Shen, Q., \& Li, H. (2004). Design of spatial decision support systems for property professionals using MapObjects and Excel. Automation in Construction, 13(5), 565-573.

Muhanna, W. A. (1993). An object-oriented framework for model management and DSS development. Decision Support Systems, 9(2), 217-229.

Qian, G., Wang, H., \& Feng, X. (2012). Generalized of Hesitant Fuzzy Sets and their application in decision support system. Knowledge-Based Systems, 37, 357-365.

Sanchez, E., Toro, C., Artetxe, A., Graña, M., Sanin, C., Szczerbicki, E., ... \& Guijarro, F. (2013). Bridging challenges of Clinical Decision Support Systems with a semantic approach. A case study on breast cancer. Pattern Recognition Letters, 52, 237-248

Siskos, Y., Zopounidis, C., \& Pouliezos, A. (1994). An integrated DSS for financing firms by an industrial development bank in Greece. Decision Support Systems, 12(2), 151-168. 